\title{
Seguridad Internacional en los años ochenta
}

VIOLENGIA Y ANTIVIOLENCIA

De todos Ios impulsos humanos, tal vez solamente el hambre constituye una fuerza tan poderosa como el deseo de escapar a la muerte causada por la violencia física. Por supuesto que existen individuos que buscan la violencia e, incluso, que buscan una muerte violenta. Pero la mayor parte de la humanidad considera que esas personas se encuentran mentalmente enfermas, del mismo modo que se considera que aquellas que ponen en peligro sus vidas por rechazar los alimentos sufren de un desorden psíquico. El hambre y el terror son responsables, juntamente, por una buena parte del estado actual de la civilización. Los seres humanos prehistóricos se agrupaban en bandas para unir sus fuerzas con el objeto de recolectar alimentos y protegerse contra los enemigos. Sus primeras agrupaciones familiares y tribales se convirtieron, eventualmente, en las sociedades globales organizadas en los estados nacionales que conocemos en la actualidad.

Sin embargo, en forma tan irónica como terrible, mientras que el hambre de la humanidad ha sido la fuente de un extenso y elaborado desarrollo de la agricultura, su urgencia de escapar a una muerte violenta ha provocado la aparición de medios para matar cada vez más efectivos. Miles de generaciones han creído que la mejor protección contra la violencia es la contraviolencia - a veces, en verdad, la violencia intimidatoria y preventiva. Y si, como dijo una vez el Dr. Johnson, nada aclara tanto la mente como la perspectiva de ser ahorcado, nada desata el genio inventivo como el miedo a ser destruido por el enemigo. En los tiempos modernos, la capacidad de los hombres parar exterminarse mutuamente ha crecido en forma mucho más rápida que su capacidad para asegurarse una alimentación adecuada -y ello sin restar importancia a los enormes avances logrados en la tecnología agrícola durante los últimos cien años. Como resultado de gigantescas inversiones, hoy existen los medios para destruir

* Introducción a un libro del autor que, con este mismo título se encuentra actualmente en prensa. 
tan fácil como eficientemente toda forma de vida humana en el planeta. Sin embargo, nuestros medios para distribuir alimentos $y$, por lo tanto, para nutrir adecuadamente esa vida humana, son trágicamente insuficientes.

Los años que restan del siglo $\mathrm{xx}$ verán grandes avances en un poder para destruir, lo que con mayor probabilidad ocurrirá en los dominios de la irradiación nuclear y de los medios químicos. Aunque el poder tradicional de los nuevos armamentos no podrá compararse con la diferencia que introdujeron los explosivos basados en la fusión nuclear en 1945, o en la fusión termonuclear en 1954 -o, para estos efectos, por el uso de la pólrora hace 500 años- dicho poder será, en el sentido más literal de la palabra, respetable. Ello ocurrirá a menos que intervenga una voluntad política poderosa y concertada, y una efectiva acción política.

La voluntad y la acción política constituyen el objeto principal de este estudio. Hoy no existe $-y$, en verdad, no ha existido desde hace mucho tiempo- falta de ingenio para diseñar medios apropiados para contener la violencia v, de esta manera, reducir su impacto y su incidencia. Muchos visionarios políticos a través de los siglos han propuesto innumerables esquemas para organizar muchos nuevos y también más felices. Algunas de ellas, como la visión de Emannuel Kant acerca de una "paz perpetua", se han basado en la hermandad. Otras han estado enraizadas en la necesidad de un imperio o un gobierno mundial: es mejor colocarse bajo la soberanía absoluta de una autoridad todopoderosa o de un Leviathan tiránico, como escribió Thomas Hobbes hace tres siglos, que arriesgar su propia vida en las inciertas guerras causadas por la competencia entre pequeños poderes soberanos. Es mejor colocar todas las armas nucleares bajo el control de una agencia mundial, afirmaba Bernart Baruch en 1945, cuando los Estados Unidos tenían el monopolio atómico, que correr el riesgo de que ellas se dispersaran en las manos de gobiernos potencialmente conflictivos.

En cuanto a esos esquemas de ingeniería política, en su mayor parte han sido propuestos sobre la base de heróicas presunciones acerca de la existencia previa de actitudes de tolerancia, moderación y confianza, cualidades que han demostrado ser notablemente escasas, no sólo dentro de los estados nacionales, sino que mucho más aún en la arena mundial. Por muchas razones, algunas más válidas que otras, los gobiernos no han considerado favorable a sus intereses renunciar a los cursos de acción que habían programado o a sus respuestas espasmódicas frente a las acciones de terceros países. Por 
razones generalmente valederas tampoco han querido someter a otros gobiernos o a autoridades supranacionales el poder de adoptar decisiones que, a su juicio, comprometían su propia supervivencia. Esa facultad es, naturalmente, la esencia misma de la soberanfa nacional, y la soberanía nacional sigue estando viva como motivación de la conducta de los estados en la última parte del siglo xx.

Gualquier intento de hacer el- mundo más "seguro" durante lo que queda de este siglo se hará a pesar de la persistencia de la noción tradicional del estado soberano, con una alta probabilidad de que los lineamientos del sistema estatal que actualmente existe continuen por mucho tiempo todavía. Esto no significa que muchos estados no vayan a ser mucho más o mucho menos capaces de garantizar su propia seguridad contra daños físicos con el mismo grado de confianza en que están en condiciones de hacerlo en la actualidad. Entonces, como ahora, esa capacidad variará ampliamente de estado en estado, dependiendo de las circunstancias en que se encuentre cada uno. Por supuesto, esa capacidad será influenciada por los cambios que ocurran en la tecnología de la violencia. En muchos casos, será solamente ilusoria: las armas modernas, en la mayor parte de los casos, dejan en la indefención a los estado. Pero tanto los gobernantes como los gobernados seguramente procurarán preservar la ilusión de una soberanía entendida tal como ha sido concebida hasta ahora, en lugar de optar por los posibles beneficios que en el largo plazo traería la disolución de las soberanías nacionales en favor de estructuras políticas más amplias.

\section{EL SIGNTFICADO DE LA "SEGURIDAD"}

El concepto de "seguridad, por supuesto, tiene muchos significados. En años recientes, los investigadores y publicistas han enfocado su atención hacia lo que ha dado en llamarse las "otras dimensiones de la seguridad", incluyendo la seguridad en el suministro de alimentos y energía, la provisión de servicios de salud, Ia pureza del aire y el agua, $y$ otros aspectos similares. Una persona $-o$, en realidad, una comunidad de personas- no puede sentirse segura cuando está malnutrida, débilmente protegida contra inclemencias climáticas o amenazada por epidemias mortales. Un estado nacional no puede sentirse seguro si depende de otros estados con respecto al suministro de materias primas fundamentales, tales como el petróleo o el uranio enriquecido. Sin duda no se sentirá seguro si tales abastecimientos son repentinamente interrumpidos. 
Entendida de esta manera, la noción de seguridad comprende el concepto de "necesidades básicas", que ha pasado a formar parte del diálogo o confrontación entre el Norte y el. Sur. Del mismo modo, hoy se reconoce que los derechos políticos y civiles constituyen otros tantos aspectos del concepto de seguridad. No se trata simplemente de que los estados estén seguros, sino también los grupos e individuos que viven dentro de sus fronteras. Ellos deben sentirse seguros también frente el estado, y no sólo frente los enemigos del estado. En tiempos recientes $-y$, en verdad, a través de todo el curso de la historia- las mismas fuerzas armadas que pretendían defender la sociedad frente a ataques externos, se han convertido en frecuencia en los agentes de actos brutales de represión interna. Thomas Hobbes aconsejaba a sus contemporáneos del siglo xvrr olvidar cualquier trasgresión a sus derechos, en la medida en que el soberano que de esa manera los violaba estuviera en condiciones de asegurarles que ningún poder externo podría hacer lo mismo. En nuestro propio siglo, los voceros del autoritarismo han hecho llamados similares. Pero un alemán que hubiese aceptado el salvajismo del régimen de Hitler sobre la base de que éste ofrecía protegerlo contra los enemigos de Alemania en el exterior, difícilmente recomendaría adoptar la misma posición hoy. $\mathrm{Y}$ un actual residente de Soweto -el ghetto negro cerca de Johanesburgo- debería ser disculpado si no apreciara la seguridad que las fuerzas militares de Africa del Sur le suministran contra la amenaza de las guerrillas basadas en los países vecinos.

La seguridad en estos tres sentidos - contra los enemigos externos del estado, contra la privación de los medios necesarios para atender las necesidades básicas de la humanidad y contra la represión ejercida por el estado mismo- se encuentra con frecuencia ausente en muchos pafses en desarrollo en nuestros días. Deficitarios tanto en recursos económicos como en sus grupos dirigentes, generalmente se encuentran regidos por gobiernos que no representan a la sociedad en su conjunto sino a un estrato afluente pero escaso, seleccionado frecuentemente dentro de una minoría económica, tribal o religiosa. Esos gobiernos por lo general no desean o no son capaces de llevar adelante aquellas reformas fundamentales, que usualmente incluyen una drástica distribución de la riqueza, necesarias para satisfacer las necesidades básicas de la población y para suministrar las bases para una creçimiento equitativo. Todo gobierno depende, en última instancia, de un cierto grado de coerción, pero tales regímenes tienden a desplegar su poder coercitivo simplemente para permanecer en el poder y el peligro de que usen la fuerza represiva de que disponen 
contra la población que ellos gobiernan nunca está muy alejado de la superficie de la vida cotidiana en esos países.

La existencia de fuerzas militares y policiales numerosas y bien equipadas son, de esta manera, parte integrante de muchos regímenes contemporáneos. Tales regímenes confrontan con frecuencia enemigos externos, en disputas sobre territorio o recursos, o acerca el predominio sobre determinadas regiones geográficas. Algunas veces esos enemigos son aliados de los opositores internos de aquellos gobiernos -ya que comparten su misma ideología o pertenecen al mismo grupo racial o religioso- o simplemente son contendores regionales que ven la oportunidad de obtener beneficios para ellos mismos avivando la disensiones internas de sus vecinos.

Este estudio debe tomar en cuenta necesariamente todos estos significados del concepto de seguridad. Sin embargo, sólo tratará marginalmente los problemas referentes a la seguridad de los individuos, en cuanto a disponer de un mínimo de alimentación, vivienda, salud y educación*.

Reconocemos que este problema es la raíz de buena parte de los desordenes existentes entre las naciones así también como al interior de ellas mismas. Este estudio, sin embargo, se concentrará predominantemente en el problema de la seguridad internacional, que procura garantizar que los estados no serán el blanco de ataques físicos provenientes de fuera de sus fronteras. Pero esta preocupación no puede ser fácilmente separado del problema de la seguridad interna.

Prácticamente no existe una línea clara que distinga los enemigos externos e internos, así como tampoco para distinguir los instrumentos de que dispone un estado para combatir cada uno de estos enemigos. Incluso es cuestionable que el bienestar de la humanidad pudiera progresar si los gobiernos utilizaran la paz internacional para desencadenar la violencia contra determinados grupos $\rightarrow 0$ incluso individuosdentro de sus fronteras.

\section{La seguridad de los regimenes y la seguridad de las sociedades.}

Sin embargo, el volumen al cual sirve de introducción este trabajo no trata directamente acerca de la protección de los derechos humanos.

*Este es el foco de otros trabajos del Proyecto 1980. Ver, interalia, Gunnar Adler-Karlsson, "Eliminating Absolute Poverty: An Approach to the Problem", en W. Howard Wriggins y Gunnar Adler-KarIsson, Reducing Glogal Inequities, 1978, págs. 121-80, y Roger D. Hansen, Beyond the North-South Stalemate, 1979, esp. págs. $245-78$. 
Dicho volumen tratará directamente de las relaciones entre gobernantes y gobernados. Una premisa central consiste en que, al reflexionar acerca de la seguridad internacional, es crucial efectuar una distinción entre la seguridad y el bienestar de las sociedades -incluyendo a toda la población de un país y a sus instituciones políticas y sociales- y la seguridad y bienestar de los regímenes. Muchas decisiones adoptadas y muchas acciones emprendidas para fortalecer la "seguridad nacional" son diseñadas, de hecho, para promover los intereses, el bienestar e incluso la seguridad física de un círculo de personas - a veces de una sola persona- que se encuentra a la cabeza de ese gobierno en particular. En muchos casos, esas acciones pueden poner en peligro la propia seguridad de la nación en cuyo nombre fueron realizadas. Un régimen puede manipular animosidades regionales, incrementando más bien que atenuando las actitudes hostiles preexistentes, hasta llegar al borde de la guerra. Puede hacer eso por considerar que una atmósfera de guerra podría reunificar a los grupos opositores internos, o por el contrario proporcionarle un pretexto para aplastarlos, sirviendo de excusa al fracaso del régimen para solucionar los problemas internos. La junta militar griega hizo eso en relación con el problema de Chipre en 1974; el resultado fue su propio derrocamiento y una continua y creciente exacerbación de las tensiones entre Grecia y Turquía. O un régimen puede fortalecer sus fuerzas armadas, supuestamente para enfrentar una potencial amenaza externa, pero de hecho para ganar la lealtad del cuerpo de oficiales sobre el cual depende en definitiva para retener el poder. La lealtad de las fuerzas armadas es necesariamente una preocupación muy importante de quienes se encuentran en el poder; para conservarla, esos gobernantes encuentran crecientemente necesario compartir el poder (y la riqueza) con los mandos medios. Las masivas adquisiciones de armas realizadas con el Sha de Irán durante los años 1970 pueden haber sido motivadas en buena medida por este tipo de consideraciones. Pero en 1978 descubrió que la paz de Trán y su propio control sobre el poder habian sido destruidos, no por las fuerzas armadas, sino por los trabajadores iraníes cuyos salarios habían sido mantenidos muy bajos por el gobierno a fin de destinar esos recursos a construir símbolos que enaltecieran el prestigio nacional. Entre tanto, el fortalecimiento militar de Irán fue emulado por otros estados en el Golfo Pérsico, especialmente por Irak y Arabia Saudita. Es probable que ninguno de ellos se encuentre ahora más seguro, en comparación con los otros, de lo que lo eran antes que comenzara la carrera armamentista hace un decenio, y ciertamente que si una 
guerra estallara en el Golfo Pérsico, sus efectos serían hoy mucho más devastadores de lo que habrían sido en los años 1960 .

-No sólo entre los relativamente frágiles cuerpos políticos de los países en desarrollo es posible distinguir entre la seguridad de las sociedades $y$ la seguridad de los regimenes. La "seguridad nacional", o. la "defensa de la tierra de los antepasados" en casi todos los países eș un disparador cargado de emociones que está a la espera de ser presionado, y hay algunos gobiernos que constantemente están jugando con él, manipulando los símbolos del poder militar para su propio beneficio. Eṇ las sociedades democráticas liberales, donde los partidos de oposición tienen un acceso tan fácil a los medios de comunicación çomo los propios gobiernos, la tentación es especialmente grande. La historia de la mayoría de las democracias occidentales. éstá llena de quejas efectuadas por la oposición en el sentido de que los gobiernos, por inadvertencia o por designio, han puesto en peligro la seguridad de la nación. Y así como un ex gobernador, racista de Alabama declaró una vez que nunca más volvería a permitir a sus demagógicos' opositores blancos que lo alinearan con la causa de los negros, así también los gobiernos occidentàles con:frecuencia han encontrado más fácil silenciär la oposición alineándola con los comunistas y optando por crécientes gastos defensivos y posiciones cada vez más duras en las negociacionés sobre problemas de seguridad entre el Este y el Oeste. $\therefore$ Dentro de los cerrados sistemas políticos de los países comunistas, donde la ópósición organizada está prohibida y los gobiernos monopoilizan todos los medios de comunicación, también hay una poderosa pólítica de seguridad. Pero esa es una política confinada a las cámaras de los comités centrales, donde los aspirantes a los más altos cargos maniobran para obtener el apoyo de los diversos grupos burocráticos que compiten por la distribución de los recursos nacionales. Dentro đé la mayoría de los estados comunistas las fuerzas armadas son: crucialmente importantes en comparación con otras burocracias contendientes. En todos los parses comunistas la policía de seguridad ocupa un lugar central. Las fuerzas militares y la policía de seguridad. se expanden en épocas en que se percibe un peligro externo; en cambio, ellas $y$ sus presupuestos se desvanecen cuando las tensiones internacionales se aplacan. La historia reciente tanto de los Estados. Unidos como de la Unión Soviética provee ejemplos instructivos de régímenes que han manipulado temas vinculados con la seguridad nacional para su propio beneficio. Los líderes de ambos países han adoptado importantes decisiones en materia de gastos militares porque sentian que eran necesarios para asegurar la mantención del 
apoyo de" los comandantes đe làs fuerżas armadas." En tảles instancias no estaban temerosos de algo parecido a un golpe de estado pox parte de generales o almirantes desilusionadios. Pero sabían que los: servicios armados tenían un peso 'decisivo" en círculos 'cuyo apoyo' por diferentes razones, consideraban vital para mantenerse en el poder: en - Ia Unión Soviética, el Politburo, iv tal, vez algunos miembros adicionales del Comité Central del Partido Comunista; en los Estadoş Unidos, el Congreso y algunos sectores de la opinión: pública. Alg̈unas de esas decisiones vinculadas con gastos militares han complicado profundamente la tarea de alcanzar acuerdos en materia de limitación armamentista, los cuales podrían incrementar la estabilidad de las relaciones estratégicas entre los Estadọs Unidos y lả Ưnión Sovié= tica, y alejar la probabilidad de unna guerra entre ambas potencias:

Del mismo modo, ambos países se han embarcado en operaciones militares porque sus respectivos líderes consideraban dichas operaciones necesarias para su propia supervivencia política, y no porqué la falta de estos operativos hubiera puesto en peligro de alguná manera demostrable lä seguridad física de sus sociedadés. Lyndon Johnson envió unidades terrestres y marítimas a Santo Domingo en 1965 porque pensaba que su presidencia no podría sobrevivir "otra Cuba", y no porque un régimen comunista en la Répública Dominicana pudiera amenazar directamente a los Estados Unidos. (De hecho, los comunistas desempeñaron roles insignificante entre'- los insurgientes dominicanos; incluso si estos últimos hubieron triunfado, lo más probable es que el resultado no hubiera: sido un régimen comunista. Pero Johnśon no quería correr riesgos).. En Moscú, tres años después Leonidas Brezhnev y sus colegas en el Politbúro desen: cadenaron una invasión en nombre del Pacto de Varsovia para derribar el gobierno de Checoslovaquia porque temía que las medidas liberálizadoras que Alejandro Dubçek trató: de introducir, inspirarían damandas similares en la Unión Soviética -demandas que no podrían: ser satisfechas sin erosionar la pretensión del régimen soviético a ejercer el poder absoluto $y$, por lo tanto, sin alterar profundamente las relaciones entre el régimen y la sociedad:

El propósito de hacer estas distinciones entre la seguridad de los regímenes y la seguridad de la sociedad no consiste en sugerir una dicotomía rígida. En algunas instancias, $\gamma$ para algunos propósitos; no se observa mayor utilidad en distinguir entre intereses del régiminèn e intereses societaless. Contrariamente a las muy difundidas suposiciones de los propagandistas del socialismo y del populismo, es muy raro el caso en que un gobierno (especialmente si es capitalista, "como. 
la demonología en boga gusta de calificarlos) quiere hacer la guerra mientras que el pueblo (especialmente si se le da la opción de hacerlo) trata de conseguir la paz. Pero frecuentemente es imposible explicar las políticas de seguridad de un gobierno determinado - sus elecciones en materia de adquisición de armamentos, sus respuestas frente a las iniciativas de otros poderes regionales o sus decisiones sobre la paz y la guerra- sin distinguir entre la seguridad del régimen y la seguridad de la sociedad.

Dar importancia a esta distinción no significa simplemente decir que las políticas internas afectan a la política exterior, y que las decisiones de política internacional de un gobierno no pueden ser comprendidas sin tener una percepción acerca del contexto político doméstico, ya que por supuesto eso no es posible. Pero la política de la sobrevivencia representa una categoría muy especial entre las políticas internas. En algunas instancias, como en el caso de Lyndon Johnson y de la intervención en República Dominicana, sólo la supervivencia política estaba en juego. En otras instancias, como ocurre frecuentemente en los países en desarrollo, lo que está en juego puede ser muy bien la supervivencia física de sus dirigentes, si sus regímenes son derribados por la oposición interna. Por eso, para retener el poder están dispuestos a arriesgar la seguridad -e incluso la supervivenciade su propia nación, para no mencionar la de otras.

Simplemente con deplorar este fenómeno se contribuye muy poco a la causa de la paz. Los líderes que sienten que sus vidas están en juego probablemente no retrocederán frente a decisiones políticas que puedan elevar las tensiones internacionales, simplemente porque algunos analistas neutrales denuncien el cinismo de su comportamiento, aunque otros dirigentes que sólo arriesgan su supervivencia política tal vez lo hagan. Aquellos que buscan reducir la incidencia y la intensidad de la violencia entre las naciones pueden verse obligados a tomar en cuenta las necesidades políticas de sus gobernados. Cada hombre tiene su precio: también lo tiene cada líder. En la conducción de los negocios del estado es esencial descubrir cuál es el precio real de cada uno de ellos. Al final, uno puede estimar que es demasiado alto, como lo hicieron los gobiernos británico y francés cuando decidieron oponerse a Adolfo Hitler en septiembre de 1939, o como lo hicieron nuevamente -recordando a Hitler- cuando lanzaron la invasión de Suez contra Gamal Abdul Nasser en octubre de 1976. Pero no hacer un esfuerzo por estimar cuál es el precio, para un estadista, equivale a un acto de negligencia criminal. 
Hitler y Nasser fueron en realidad asimilados en las torturadas obsesiones de Anthony Eden, quien presidió sobre la invasión de Suez como Primer Ministro del Reino Unido, y que había renunciado al Ministerio del Exterior dos decenios antes porque sus colegas no estaban dispuestos a oponerse a la expansión del nacismo.

Ellos son invitados por igual aquí a no hacer la misma ecuación, sino que a marcar un punto de contraste, en el sentido de que es posible imponer ciertas acciones para revisar el orden internacional existente con más legitimidad que otras. En 1939 pocas personas fuera de Alemania dejaban de considerar como ilegítimos los métodos empleados por Hitler para derribar el régimen impuesto sobre ese país por el Tratado de Versalles en 1919, de la misma manera como ellos seguramente habrían cuestionado la legitimidad del tratado mismo. Pero en 1956 habian muchas personas, incluso en Francia y Gran Bretaña, que sentían que Nasser estaba actuando correctamente al derogar en forma unilateral un tratado que durante 75 años había privado a Egipto de todo control sobre un canal que lo cortaba en dos mitades.

\section{CAMIBIO PAGIFIGO, REVISIONISMO Y RESISTENCIA}

Hitler y Nasser plantean el dilema del cambio pacífico. Ninguno de ellos quería la guerra, ni menos aún con sus principales adversarios. Ambos deseaban revisar un orden internacional que despreciaban. Ambos necesitaban lograr éxitos espectaculares en su politica exterior por razones internas. Ambos reaccionaron contra con lo que consideraban la intolerable resistencia de ciertos gobiernos extranjeros. Ante la imposibilidad de lograr el cambio pacífico, ambos escogieron el camino de los hechos cumplidos.

Al final, Nasser logró buena parte de lo que deseaba y Hitler obtuvo lo que merecía. Pero los costos de resistir a Hitler, para la posteridad y para sus propios contemporáneos, fueron gigantescos.

El cambio pacífico es el otro ládo de la moneda de la seguridad. Hay dos maneras de tratar con un estado revisionista. Una consiste en acceder a sus deseos de cambio o, en todo caso, a algunos de ellos Se trata de una política comunmente denominada de "apaciguamiento". Equivocadamente este término ha adquirido un valor peyorativo. Su mala fama proviene de las políticas británica y francesa en los años 1930. Sin embargo, el término debería ser valorativamente neutro. A veces, en ciertas circunstancias, la aquiescencia a las demandas revisionistas de un estado resulta correcta y apropiada. Ello compensa 
la debilidad de los mecanismos existentes para inducir a los estados a abandonar estructuras superadas. El Tratado de la Liga de las Naciones expresaba claramente la esperanza de que "de tiempo en tiempo" la Asamblea de la Organización pudiera "recomendar la reconsideración de aquellos tratados que se hubieren vuelto inaplicables y la consideración de aquellas condiciones internacionales cuya continuidad pudiera poner en peligro la paz mundial". Por desgracia esta esperanza aún no se ha cumplido. Ni la Liga; ni las Naciones Unidas, han sido motores eficaces de cambio pacífico, salvo en un aspecto importante, cual es la descolonización, un proceso en que la creciente mayoría de pueblos de color en el seno de las Naciones Unidas logró aplicar presiones efectivas para reducir el número de sociedades de color dominadas por minoría blancas.

La segunda manera de enfrentar las demandas adicionistas consisten, naturalmente, en resistirlas. La resistencia requiere tanto los medios como la voluntad de llevarla ai cabo. Dependiendo de cuán. vigorosamente y contra quién esas reclamaciones se planteen, la resistencia a ellas puede requerir también de una organización. Fue nece. sario emplear los esfuerzos concertados de los gobiernos norteamericano británico y francés para frustrar la tentativa soviética de revisar el régimen de ocupación internacional de la Alemania de postguerra a través del bloqueo de Berlín, en 1948. Y fue necesario construir una alianza política y militarmente más estructurada, la Organización del Tratado del Atlántico Norte (OTAN), para infundir a las sociedades de Europa Occidental la confianza en que ellas podrían resistir las subsiguientes demandas revisionistas soviéticas. Al otro lado de la frontera ideológica que dividió en dos partes a Europa, los gobiernos comunistas se dieron cuenta que necesitaban una alianza todavía más rígida y centralizada para contener los planteamientos revisionistas mucho más poderosos $-\mathrm{y}$ la amenaza de lanzar una intervención militar de caso de una revolución popular- provenientes del Occidente.

La conveniencia de resistir los esfuerzos escaminados a revisar el orden internacional existente $-\mathrm{y}$ la forma de hacerlo- se encuentra en el corazón mismo del dilema que enfrentan los gobiernos nacionâles en el campo de la seguridad. Bajo el Tratado de Versalles, en 1919, las potencias triunfantes en la primera guerra mundial impusieron a una Alemania derrotada tres tipos de penalidades - territoriales, militares y económicas. Los sucesivos gobiernos alemanes, desde entonces, trataron de revisar estos tres tipos de medidas. Con diversos grados de reluctancia, sus contrapartidas británica y francesa 
accedieron a que la República de Weimar, primeramente, y más tarde el Tercer Reich de Hitler, desconociera las claúsulas del Tratado de Versalles que exigían que Alemania permaneciera desmilitarizada e hiciera frente al pago de reparaciones de guerra. Finalmente, sólo cuando Hitler se sintió lo suficientemente fuerte como para revisar el orden territorial surgido en 1919 e incluso sólo después que el Füher se había apoderado de Austria y de Checoslovaquia y había vuelto sus ojos hacia Polonia, llegaron a la conclusión los gobiemos de Gran Bretaña y Francia de que el futuro de su seguridad dependía de la resistencia a las pretensiones alemanas. Pero, de hecho, su seguridad había sido sustancialmente erosionada cuando el revisionismo alemán se materializó en el rearme y en el repudio de lás reparaciones. Como ha observado con frecuencia Henry Kissinger, cuando uno llega a saber con certeza que un adversario intenta dañarlo seriamente, puede ser ya muy tarde para organizar una resistencia efectiva. Es por eso que el gobierno israelí lanzó su guerra relámpago en junio de 1967 tan pronto como Nasser rechazó la supervisión de las fuerzas de las Naciones Unidas y anunció que Egipto cerraría los estrechos de Tirán a los barcos fletados por Israel. Los israelitas no esperaron thasta cersiorarse de si Nasser tenía efectivamente la intención de cumplir sus amenazas. $\mathrm{Y}$ es por eso que algunas voces en el Occidente exigieron una guerra preventiva cuando los países árabes miembros de la Organización de Países Exportadores de Petróleo (OPEP) cuadruplicaron los precios del petróleo en 1973 y en 1974. Si las. naciones industrializadas no actuaban de inmediato y enérgicamente para revestir esos aumentos, argumentaban esas voces, el balance de poder se inclinaría excesivamente en favor de los países productores de petróleo. Con su ingente riqueza, recientemente adquirida, esos países serían capaces de adquirir armas que haría enormemente costoso para los países consumidores de petróleo el uso de la fuerza contra ellos en el futuro. $Y$ el aumento de los precios que generaría esa riqueza tendría el efecto adicional de retardar el crecimiento económico de las naciones industrializadas, las cuales por consiguiente verían disminuida su capacidad para mantener las ventajas militares de que entonces disponían. Esas predicciones demostraron, en general, haber sido correctas.

Como queda ilustrado a través de ese ejemplo, hasta los años 1970 los bajos precios del petróleo habían formado parte del orden. internacional que gobernaba las relaciones entre los países industrializados. y los demás miembros del sistema internacional. Mediante el drástico: 
aumento de esos precios -aceptado por las potencias occidentaleslos países miembros de la OPEP lograron revisar exitosamente dicho orden, hasta el punto en que los precios más altos del petróleo iy los mayores beneficios para los países productores llegaron a constituir la norma. Pero los países árabes miembros de la OPEP no sólo elevaron los precios del petróleo durante el período 1973-1974, sino que también embargaron los embarques de petróleo destinados a los Estados Unidos y a otras de las grandes naciones importadoras de petróleo, a manera de retaliación por su supuesto apoyo a Israel durante la guerra de octubre de 1973 en el Medio Oriente. Esas medidas tampoco provocaron ninguna reacción de parte del Occidente, lo cual se debe al menos en parte a que el embargo no fue demasiado efectivo. Pero ellas inspiraron, en cambio, una advertencia de Henry Kissinger, entonces Secretario de Estado de los Estados Unidos, en el sentido de que un embargo, en el futuro, podría dar lugar a una reacción más enérgica. Los Estados Unidos, señaló, no permitiría impunemente ser "estrangulado".

Tanto el agudo y repentino aumento de los precios del petróleo como la ausencia de una rápida respuesta occidental al embargo árabe, aparte de la advertencia verbal de Henry Kissinger, fueron en gran medida una expresión de los años 1970. Un decenio antes los países miembros de la opep hubieran carecido de la confianza necesaria para actuar unilateral y drásticamente elevando los precios del petróleo, y mucho menos para lanzar una guerra económica (porque eso fue, de hecho, el embargo) contra los Estados Unidos. La confianza que ellos mostraron en el período de 1973-1974 provenía de dos fuentes, a saber, las cambiantes condiciones de la economía mundial y las cambiantes percepciones relativas a la distribución mundial del poder y a la utilidad y la "legitimidad" de emplear la fuerza militar. Cada uno de estos factores merece considerable atención en cualquier debate acerca del problema de la seguridad internacional en los años 1980.

\section{LOS REGURSOS DE PODER}

El acceso a los recursos naturales ha sido siempre una importante causa de conflictos internacionales. Pero sólo en los años 1970 llegó a comprenderse universalmente el hecho de que la oferta mundial de algunos de los recursos más importantes tenía límites finitos, y que algunos de estos límites podían ser alcanzados lo suficientemente pronto como para reducir severamente las posibilidades de crecimiento económico de algunas naciones $y$, eventualmente, del mundo 
entero. Esas percepciones exacerbaron, por supuesto, la preocupación. en torno a un continuo acceso a determinados recursos. Ellas implicaron también que los países ricos en ciertos materiales adquirieran mayor gravitación en el escenario internacional y, por consiguiente, nuevas oportunidades para alterar los términos de intercambio mundiales en su propio provecho y en contra de los países industrializados más pobres en recursos naturales.

Cuando los gobiernos de la opep desafiaron exitosamente el antiguo régimen basado en los bajos precios del petróleo, los productores de otras materias primas - particularmente en el caso de la bauxita, el cobre y los sulfatos- trataron de emularlos. El hecho de que en general estos otros países no hayan sido tan exitosos en su intento no se derivan de ningún modo de la resistencia deliberada por parte de las naciones importadoras sino de las características especiales de la oferta y la demanda de petróleo. EI petróleo es crucial para las economías de los países industrializados. Ninguna fuente alternativa de energía se encuentra disponible a corto plazo. Y la distribución geográfica de las reservas de petróleo colocan una gran cuota de influencia en las manos de unos pocos países exportadores de ese combustible. Esa influencia no existía hace solamente un decenio. Ahora existe en parte a causa de que el consumo de petróleo ha aumentado tan rápidamente en todo el mundo, pero también a causa de que sólo hacia fines de Ios años 1960 la economía de los Estados Unidos -la economía más grande del mundo- comenzó a depender sensiblemente del petróleo importaclo. En los años anteriores los Estados Unidos eran por sí mismos exportadores de petróleo. Hasta los años 1970, por lo tanto, los intentos de la opeP para aumentar drásticamente los precios mundiales del petróleo hubieran sido útiles.

Un proyecto de investigación sobre las perspectivas del decenio de 1980 conducido por Uzi y Rut Arad concluye que durante el resto del presente siglo el petróleo será un producto único en cuanto al grado de influencia que deparará a los países productores. Los investigadores mencionados consideran que en ningún otro producto la dependencia de los países importadores con respecto a unos cuantos exportadores será tan importante como en el caso del petróleo. Arabia Saudita y otros países productores de petróleo en el Golfo Pérsico podrían restringir substancialmente su producción y conservar su capacidad para pagar todas las importaciones que necesitan para sostener su desarrollo. Ambos investigadores destacan el cromio, el platino, el estaño y la bauxita como otras tantas materias primas en que la distribución 
geográfica del recurso y la dependencia asimétrica entre países importadores y exportadores podría hacer posible concebir una manipulación exitosa de la oferta. Pero ellos llegan a la conclusión de que solamente en el caso del petróleo la dependencia de los países importadores será suficientemente grande como para crear y mantener la posibilidad de un conflicto armado. $Y$ aún en el caso dej petróleo, predicen estos investigadores, aquel conflicto armado sería más probable, no tanto entre productores y consumidores, sino entre estados vecinos que podrían ir a la guerra por hacer valer sus derechos sobre determinadas reservas, especialmente tratándose de reservas localizadas por la plataforma continental en donde las reclamaciones territoriales son más disputadas*. Pero lo anterior determinó que los norteamericanos y sus dirigentes políticos se sintieran mucho menos deseosos que en el pasado de contemplar el uso de la fuerza militar para intervenir en el Tercer Mundo, particularmente con un propósito moralmente tan dudoso como el de revertir los precios de un recurso cuyas condiciones de venta debe ser legitimamente determinada por los países productores.

Sin embargo, el embargo árabe que acompañó el aumento de los precios fue enteramente pacífico. Los principales países productores se limitaron a despachar menos petróleo, y a asegurar que ningún embarque fuera dirigido hacia ciertos países, particularmente hacia los Estados Unidos. Si ellos hubieran intentado cualquier forma de interferencia física con los cargueros que ya se encontraban en el mar, o con los embarques efectuados por otros países productores, tales como Irán o Venezuela, que no observaron el embargo, los Estados Unidos ciertamente hubieran señalado la existencia de un obvio casus belli y hubieran respondido con la fuerza -quizás incluso con la fuerza suficiente no sólo para romper el embargo sino también para revertir la tendencia de los precios.

Sin embargo, tal como se desarrollaron los acontecimientos, no sólo no se disparó sino que ni siquiera se amenazó con disparar un solo tiro. Esta circunstancia dio lugar a una serie de comentarios; algunos cle los cuales deploraban mientras que otros aplaudían el hecho de que la utilidad del uso de la fuerza militar parecía estar declinando, En otros períodos, anotaron diversos comentaristas, que ninguna colección de pequeños y militarmente débiles estados similar a los países de la OPEP hubiera podido atreverse a tomar medidas unilate-

* Ver Uzi. B. Arad y Rutw. Axad., Scarce National Resources in Potential Conflict., en Arad et al., Sharing Global Resources, 1979. 
rales tan profundamente antitéticas con Ios intereses de los más grandes y militarmente poderosos miembros del sistema internacional. Pero durante los seis decenios que siguieron a la primera guerra mundial se había registrado una creciente aceptación del principio de que el uso de la fuerza armada por estados relativamente poderosos contra estados relativamente débiles es, de algún modo, ilegí. timo. E incluso en aquellos casos en que era un pais débil el que iniciaba una confrontación militar, se esperaba que el país más fuerte respondiera con moderación, en lugar de utilizar todos los medios que su poderio colocaba a su disposición.

No hay dudas de que el sistema internacional contemporáneo ha institucionalizado la proscripción del uso de la fuerza. Dicha proscripción es el producto de una creciente democratización de la política interna en los países industrializados, del creciente poder destructivo de las armas modernas - sobre todo de las armas nucleares- y de la fuerza creciente del principio de la soberanía nacional. Cada uno de eșos desarrollos ha sido comentado ampliamente en otras partes, $y$ lo será en otras secciones de este ensayo*. Pero en este punto el tercero de estos factores requiere algún análisis.

\section{La conquista territorial y la penetración fronteriza.}

De todas las características del sistema internacional contemporáneo que no pudieron ser predichas por las generaciones anteriores, tal vez la más dramática sea la proliferación de naciones estados, cada uno de los cuales cuida celosamente su soberanía. Sus fronteras pueden ser el producto de tratados coloniales entre distantes gobiernos europeos; su población puede incluir minorías (o incluso mayorías) raciales totalmente opuestas a la autoridad del gobierno que en ese momento prevalece en la capital y que preferirían, ya sea formar un estado propio, o amalgamarse con un estado vecino. Pero una vez que sus fronteras son reconocidas por la comunidad internacional, täles fronteras se congelan, y el gobierno que se cobija trás ellas se mostrará tan poco dispuesto a permitị su revisión como a renunciar voluntariamente a cualquier otro atributo de su soberanía. Sin embargo, Ia ironía de esta situación consiste en que en muchas instancias - casi en todos los casos en que se encuentran involucrados estados débiles y pequeños e incluso también cuando lo están los estados

*El autor se refiere al libro del cual forma parte este trabajo, al que se hacfa referencia en un comienzo. 
más fuertes y más grandes- sus fronteras son diariamente penetradas y su soberanía, erosionada. Los invasores no son soldados extranjeros sino que las fuerzas económicas internacionales que limitan profundamente la gama de decisiones que un gobierno puede adoptar para manejar su propia economía. Por supuesto, la diferencia es crucial: en una instancia, la ilusión de soberanía e independencia se conserva, mientras que en la otra es destruida.

La misma permeabilidad y fragilidad de la mayoría de las naciones estado contemporáneas representa dudablemente un factor central que contribuye al énfasis de nuestro tiempo en el principio de la soberanía nacional y en la inviolabilidad de sus fronteras reconocidas de un estado. No solamente los grandes poderes consideran que el uso de la fuerza militar para controlar y mantener territorios es rara vez factible, sino que eso también les ocurre a los estados más pequeños. Cuando Somalía invadió Etiopía en 1978, reclamando la región contigua de Ogadén, un territorio habitado casi enteramente por somalíes que acogieron al ejército invasor como a libertadores, su acción fue recibida con una desaprobación casi universal -al menos de parte de los gobiernos. El principio de la autodeterminación nacional es aplaudido en todas partes, en la medida que aquellos que intentan ponerlo en práctica procuran derribar gobiernos coloniales o regímenes blancos en el sur de Africa. Pero cuando aquellos que invocan ese principio lo hacen para desprender una parte de un estado establecido, tal como los Ibos lo hicieron en Nigeria cuando intentaron formar Biafra, generalmente encuentran que su apoyo se limita a un puñado de liberales que toma la consistencia en serio.

Esto no quiere decir que en la actualidad las guerras territoriales sean algo raro. Las luchas por Ogadén y por Biafra son buenos ejem plos de ello -aunque la última, por supuesto, jurídicamente constituyó una guerra civil. La lucha entre Israel y sus vecinos árabes se planteó en torno a muchas cosas, pero los principales intereses en disputa fueron territoriales, y estos intereses han sido también cruciales en el conflicto entre la UUnión Soviética y China. Es probable, asimismo, que la creciente importancia de los recursos localizados en las zonas marítimas adyacentes a las costas, tales como los yacimientos minerales o las reservas de gas y de petróleo, den lugar a conflictos armados sobre islas deshabitadas que hasta ahora habian sido consideradas despreciables. Sin embargo, lo que la mayor parte de los conflictos territoriales contemporáneos tienen en común, consiste en que por 
lo general ellos se plantean sobre territorios cuyo status nunca ha sido objeto de pleno reconocimiento internacional. La mayor parte de los países árabes jamás reconocieron la legitimidad de las fronteras del estado de Israel posteriores a 1948, para no hablar siquiera de sus títulos a los territorios que ocupó en 1967. El gobierno actual de China sostiene que sus fronteras con la Unión Soviética fueron impuestas a sus predecesores por los imperialistas de la época de los zares y que, por consiguiente, deben ser revisadas en favor de China. $Y$ las islas que en muchas regiones son en la actualidad objeto de disputas son típicamente aquellas cuyos títulos jamás han sido resueltos, pero cuya propiedad fue considerada de nula importancia hasta que llegaron a convertirse en una clave para el acceso a los recursos circundantes.

Guerras civiles, conflictos entre comunidades y paises divididos.

Gon todo, las disputas territoriales generalmente no conducen a conflictos armados, y los objetivos de las partes contendientes son casi invariablemente modestos y limitados, en marcado contraste con las guerras de conquista que caracterizaron los períodos anteriores. Las principales excepciones son las guerras civiles, en las cuales los insurgentes típicamente buscan reemplazar totalmente a los gobernantes actuales, así como también aquellas guerras cuasi-civiles que de tanto en tanto amenazan estallar entre las dos mitades de países ideológicamente divididos. Así, los gobiernos establecidos en Pyonyan y Seul desearían, cada uno de ellos, unificar Corea bajo sus propios términos, de la misma manera como el régimen de Hanoi logró hacerlo en el dividido territorio de Vietnam. Las animosidades entre los dos estados alemanes ya no son tan intensas como en el pasado, o como aún lo son entre las dos Coreas, pero indudablemente hay muchos alemanes tanto en el este como en el oeste que todavía desearían reemplazar el régimen existente al otro lado del Elba por una extensión de su propio régimen.

El hecho de que ninguno de los dos estados alemanes haya hecho nunca un intento serio en tal sentido, y de que cada uno de ellos parezca preparado hoy día para coexistir en forma relativamente amistosa con el otro, se debe principalmente al congelamiento del balance militar que ha prevalecido en Europa durante los tres últimos decenios. La línea divisiva de Alemania ha resultado ser también la frontera ideológica entre las dos mitades de Europa y el límite entre 
las dos esferas de seguridad que rodean a las dos alianzas. más fuerteś de la historia. Gada estado alemán desempeña un papel principal en el bloque respectivo, el de la Organización del Trátado del Atlántico Norte y del Pacto de Varsovia, y el grado de integración de cada una de estas alianzas es muy elevado. Gualquiera que sea la evolución remotamente probable de esas dos alianzas durante el próximo decenio, sería inconcebible que los dos estados germanos fueran a la guerra sin involucrar rápidamente a sus demás socios en la alianza respectíva, particularmente a los Estados Unidos y a la Unión Sovieticá, provocando así el enfrentamiento militar directo que los dos super poderes han tratado por tan largo tiempo de evitar. La fuerte gravitación del problema alemán ha sido una de las principales fuentes de estabilidad que ha caracterizado a las relaciones de seguridad en Europa por más de una generación.

Durante los 15 años siguientes a la Segunda Guerra Mundial, el objetivo de la reunificación alemana desempeñó un papel importante en la política de los dos estados germanos, particularmente en la más populosa, poderosa y confiada Alemania Occidental. Solamente en los años 1960, cuando la naturaleza y extensión de los costos que involucraría la reunificación de Alemania fueron apreciado plenamente, ese objetivo se desvaneció. No existe un argumento más persuasivo para aceptar el status quo que el conocimiento de que, alterarlo significaría muy probablemente incurrir en costos inaceptables.

En Corea, al contrario que en Alemania, el sueño de la reunificación tiene aun considerable poder, tal vez porque una guerra entre los dos estados coreanos siempre ha parecido más probable que una guerra entre läs dos alemanias. $Y$ esto, a su vez, es así debido a que la naturaleza de las alianzas de que forman parte ambas Coreas es fundamentalmente diferente de las alianzas que mantienen las dos Alemanias. En contraste con la situación de Alemania, es posible construir un escenario plausible para una guerra en la península coreana, que pudiera involucrar sólo a las dos Coreas ý no a sǘ grandes aliados. Este no es un escenario muy probable. Pero tampoco puede ser descartado por completo, y es por lo menos lo suficientemente probable como para alentar a algunos coreanos a ambos lados del paralelo 38 para pensar que aún es posible la reunificación a. través de la conquista armada.

Las guerras civiles e internacionales libradas con motivos ideológicos, tales como las que buiscan la reunificación de países divididos, amenazan fundamentalmente à los regímenes más que a las socie- 
dades. La fracción -o la mitad del país- que lanza la guerra no desea ante todo dañar a sus compatriotas o destruir la economía del país (d.e la cual, al fin y al cabo, ellos también se benefician), sino más bien alterar los arreglos políticos bajo los cuales viven. Los ciudadanos "corrientes" - aquellos que no toman partido y que no ocupan altas posiciones dentro de los regímenes combatidos- se encuentran razonablemente a salvo. Pero el régimen mismo, como también muchas de las personas que más directamente se benefician de él, tienen su. pròpia supervivencia en juego. Esa es una de las razones de la ferocidád y laś atrocidades que con frecuencia acompañan esas guerras. El deseo de preservar a sus propios compatriotas raras veces protege a aquellos que son identificados como líderes de cualquiera de las partes contendoras.

Cuando un conflicto abarca comunidades étnicas o religiosas separadas que luchan por el dominio de un determinado trozo de territorio hay todavía mucho menos factores que morigeran al impacto de la violencia. La guerra encaminada a lograr la cesesión de Biafra con respecto a Nigeria fue particularmente brutal. También lo fue la guerra de cesesión que libró exitosamente Bangladesh contra Pakistán. En ambas instancias, las fuerzas del gobierno central estacionadas en el territorio irredentista prácticamente no acataron restricciones de ninguna especie. Otras luchas comunitarias, tales como la que se desarrolló entre griegos y turcos en Ghipre, o entre católicos y protestantes en Irlanda del Norte, han sido igualmente irrestrictas. Y la serie de guerras entre Israel y los estados árabes vecinos han sido simultáneamente internacionales y entre comunidades. Cuanto más una guerra representa un conflicto entre comunidades, más violenta es la forma en que por lo general se libra.

Las guerras civiles y otros conflictos entre comunidades raramente son susceptibles de una solución negociada. Cuando se alcanza un acuerdo, con frecuencia éste sólo representa una ficción que enmarcara la rendición total de una de las partes contendientes. Cualquier acuer. do négociado que no implique la rendición de una de las partes tiende a ser inestable. En tales casos es probable que la lucha estalle nuevamente tan pronto como la parte más agraviada reuna los medios suficientes. La guerra de Vietnam en los años 1960 es un buen ejemplo. Por aquel entonces, Vietnam del Norte buscó la victoria total que le había sido negada por el compromiso de paz alcanzado en los años 1950. El conflicto árabe-israelí, es otro ejemplo. Cada ciclo bélico en el área hà sido provocado por lá negativa árabe a aceptar los resultados de la rueda precedente. 
EI hecho de que a fines de los años 1970 comenzara a aparecer posible una solución negociada al conflicto árabe-israelí se debe al hecho de que, a lo largo de los años, éste había perdido parte de su carácter de conflicto entre comunidades y se había convertido en un conflicto "interestatal". Lo sorprendente que la primera brecha en el muro de las hostilidades provinieran de Israel y Egipto. La querella entre ambos países era la que más se parecía a una disputa convencional entre dos estados. Ninguno reinvindicaba el territorio de otro. A diferencias de los árabes residentes en el West Bank o en el río Jordán, o de aquellos que abandonaron el nuevo estado de Israel en 1948, los egipcios no poseían una historia reciente de estrechas relaciones con los israelitas. Un desierto de Sinaí prácticamente deshabitado los había mantenido separados. La ocupación del Sinaí por parte de Israel nunca había sido más que un movimiento táctico $y$, después del descubrimiento de petróleo en esa zona, sólo había pasado a adquirir una limitada importancia económica. Israel nunca disputó la soberanía final de Egipto sobre ese territorio, y los dirigentes israelitas se mantuvieron siempre dispuestos a negociar el territorio de Sinaí a cambio de la paz y del reconocimiento de su estado. Esto es lo que ellos obtuvieron mediante el tratado de paz con Egipto en 1979:

A su vez, el retiro de Egipto de las islas de los enemigos de Israel incrementó los incentivos de otros gobiernos árabes para considerar su conflicto con Israel como una disputa interestatal más que intercomunal. La hostilidad y la confianza continuaron, pero a un menor nivel de intensidad que en los decenios anteriores. A fines de los años 1970, virtualmente todos los gobiernos árabes habian reconocido el "derecho a existir" de Israel, al menos tácitamente. Ese reconocimiento redujo el conflicto de uno en torno a principios a otro relacionado con problemas concretos. Como tal, se convirtió en un conflicto susceptible de encontrar soluciones negociadas, que pudieran tener ciertas probabilidades de durar.

No sería poco razonable predecir que los años 1980 presenciarán negociaciones tendientes a reducir las tensiones asociadas con muchos de aquellos conflictos internacionales que parecían más intratables en el pasado. Por supuesto, ello incluiría el conflicto árabe-israelí. Incluiría también las disputas existentes entre los demás estados asiáticos divididos, como las dos Coreas y las dos Chinas. Podría incluir también la gran rivalidad entre el oriente y el occidente de Europa, y entre la Unión Soviética y la República Popular China, en Asia. Entre las partes involucradas en todos esos conflictos, incluso en el chino- 
Soviético y coreano, parece existir un claro reconocimiento de que los costos probables de emplear la fuerza militar para cambiar el status quo superan con mucho los probables beneficios. Esto no signi-: fica necesariamente que la propensión de los gobiernos a emplear la fuerza vaya a disminuir apreciablemente durante la próxima década. Pero en cambio significa que probablemente dichos gobiernos no recurrirán a la fuerza cuando ello implique traspasar las principales líneas de demarcación del sistema internacional, y que cuando. en definitiva recurran a la fuerza, Io harán en búsqueda de objetivos que por lo general serán más limitados que los que perseguían por medio de la fuerza en el pasado. $Y$ mientras más limitado sean los objetivos de los contendores, más probable resulta que las partes involucradas en una disputa sean capaces de llegar a una solución. negociada, si no antes de que sea disparàdo un tiro, al menos antes: de que el conflicto alcance proporciones sustanciales.

\section{INTERVENGION Y VISIBILIDAD DE LA PAZ}

Sugerir que los años 1980 traerán un cierto relajamiento de las principales tensiones que han complicado las relaciones internacionales en los años recientes, y que muchas disputas serán suceptibles: de soluciones negociadas, no equivale a decir que la próxima década será menos violenta. Después de todo, por lo general los conflictos más violentos que tuvieron lugar en el periodo siguiente a 1945 consistieron en guerras civiles, y no hay ninguna razón para pensar. que ese tipo de luchas serán menos frecuentes en el futuro. Los años: 1980 bien podrían traer guerras violentas entre partes irreconciliables, como blancos y negros en Africa del Sur o tribus en otros países. africanos o entre insurgentes revolucionarios $y$ gobernantes conservadores en numerosos países. Gualquiera de esas disputas podría asumir fácilmente las características de un conflicto internacional: en caso de que se produjera una intervención externa que, a sü. vez, diera lugar a un movimiento de rechazo a Ia intervención.

Restringir los movimientós de intervención puede constituir muy: bien uno de los problemas de seguridad más urgentes durante los años 1980. A lo largo del decenio pasado, la capacidad de la Unión. Soviética para proyectar su poder militar más allá de su propio terrie torio fortaleció continuamente hasta aproximarse al de los Estados Unidos. Si bien ambas siguieron siendo las únicas naciones que disponían de una capacidad global de intervención, los años 1970 también presenciaron la emergencia de varios poderes regionales. 
con fuerzas militares suficientemente móviles y armadas como para intentar intervenciones efectivas dentro de sus propias regiones geográficas. La intervención de Irán en Oman, de Siria e Israel en el Líbano y de Vietnam en Cambodia no constituyen sino atisbos de lo que esos y otros poderes - como por ejemplo Brasil, la India o China-serían capaces de hacer si sus intereses se vieran fuertemente afectados. Bien puede llegar el día en que esos potenciales estados hegemónicos regionales entren en colisión con las de los super poderes.

La no intervención significa aceptar el riesgo de que en ausencia de intervención pueda prevalecer una parte que representa valores indeseables desde el punto de vista de nuestros propios intereses. Puede significar también la aceptación de un régimen y de un orden político que en el campo de los derechos humanos parezca claramente indeseable como, por ejemplo, la primacía de un brutal gobierno dictatorial. Y siempre existe la posibilidad de que la abstención de un estado no sea respondida mediante una actitud similar de abstención por parte de sus rivales, en el plano regional o global, cuya propia intervención vendría así a tener el efecto de un hecho cumplido.

Sobre todo, la no intervención significa reconocer que, en contradicción con la ampliamente conocida afirmación de Maxim Litvinov en el sentido de que "la paz es indivisible", de hecho la paz es con frecuencia divisible. En los años 1930, dicho slogan procuró prevenir a las víctimas potenciales del fascismo y del nacismo en el sentido de que si no se unían para resistir la agresión serían sacrificados separadamente. Aisladamente cada uno de ellos sería derrotado; unidos, podrían prevalecer. La advertencia de Litvinov constituyó la oración fúnebre de la Liga de las Naciones. Marcó también el fracaso del principio de la seguridad colectiva, basado en la presunción de que la ruptura de la paz en cualquier lugar debería ser motivo de igual preocupación para todos los gobiernos, independientemente de su distancia respecto al área del conflicto o la extensión de sus intereses afectados por éste, y de que todos ellos deberían actuar conjuntamente para castigar al agresor. Detrás del principio de la seguridad colectiva, yace la esperanza de la disuación: si un agresor potencial sabe que su recurso al uso de la fuerza será contestado no simplemente por el estado que piensa atacar sino por las grandes potencias múndiales en conjunto, podría ser disuadido de atacar a su enemigo, en primera instancia.

En cuanto a la Liga de las Naciones, la amenaza inherente al principio de la seguridad colectiva no tuvo jamás credibilidad. Hitler 
no creyó cuando su invasión a Polonia, en septiembre de 1939, condujo a la deçlaración alemana de gueira en contra de Gran Bretaña y Francia. Y no hay que maravillarse de ello: la confusa e indecisa conducta de estos países a lo largo del decenio anterior, en respuesta a las repetidas agresiones cometidas por Japón, Italia y Alemania misma, no habían dado a Hitler. ninguna razón para pensar que las cosas serían muy diferentes en el futuro.

Las "lecciones de Munich" consistieron en que las grandes potencias deberían haberse combinado, y mucho antes para aplastar a Hitler. Y por lo tanto, al final de la guerral, el principio de la seguridad colectiva fue incorporado en la Carta de las Naciones Unidas, tal como lo había sido antes en el Convenio de la Liga. Sin embargo, sobre todo en los últimos años, ese término rara veż es empleado. Ello se debe al mayor realismo del actual periodo y al hecho de que los Estados Unidos y la Unión Soviética posean un poderío abrumadoramente superior al de los de más estados. A menos que frente a determinada disputa ambas potencias se encuentren clara. mente del mismo lado, no es posible contar con el funcionamiento automático de una acción colectiva capaz de ejercer una fuerza abrumadora que actue como un poder disuasivo que constituye la razón de ser de cualquier sistema global de seguridad colectiva. Del mismo modo, las alianzas en que las dos super potencias participan son diferentes de las del pasado. Las líneas de protección corren casi enteramente en una sola dirección: desde Washington y Moscú hacia sus aliados. La reciprocidad existe en las frases y obligaciones formales. Pero el margen de seguridad adicional que proporcionan los aliados es muy pequeño en comparación con el que garantizan las super potencias.

Las armas nucleares, campo en el cual tienen preponderancia las dos super potencias, son inherentemente destructivas del principio clásico de la seguridad colectiva. Ellas no sólo hacen virtualmente imposible cualquier "victoria" significativa de una super potencia sobre la otra, sino que además la amenaza de una escalada nuclear hace que cada una de ellas busque por todos los medios posibles evitar una confrontación militar con la otra. Consiguientemente, sus solemnes obligaciones de acudir en ayuda de sus aliados en caso de guerra, incluso a riesgo de desencadenar un ataque nuclear en gran escala en contra de su propio territorio, no pueden ser creídas por completo. El miedo de sus aliados - no exento de fundamentos y expresado con un mayor o menor grado de candor- consiste en que, llegado el momento de la decisión, el paraguas nuclear. de las super 
potencias aliadas demuestren ser una ficción más que un escudo real.

No hay nada más corrosivo del principio de la seguridad colectiva que la reluctancia a verse involucrado en un conflicto por parte de las potencias llamadas a desempeñar el rol de policía. Las armas nucleares engendran inevitablemente esa resistencia. Conforme ellas proliferan, y mientras un mayor número de naciones obtiene armas nucleares y los medios para utilizarlas, la seguridad se convierte en una realidad cada vez más divisible. Bajo las presentes circunstancias, cada super potencia podría ganar fácilmente una guerra contra cualquier estado de menor importancia, poseedor de armas nucleares. Pero incluso ahora, algunos de esos otros estados podrían infligir daños costosos a las super potencias. Es probable que sus capacidades crezcan aún más en el futuro, y que durante los próximos decenios otros gobiernos se embarquen en el mismo camino nuclear. Guando las potencias menores pueden empañar seriamente a las grandes potencias, aunque sea a un enorme costo para ellos mismos, las grandes potencias bien podrian decidir que al fin y al cabo su interés en acudir en ayuda de un aliado - quizás de uno muy distante de su propia frontera- no es tan grande. $Y$ entonces la seguridad se vería efectivamente dividida.

En .la práctica, una "paz divisible" significa tolerancia por parte de las potencias mayores de un gran número de conflictos menores. $\mathrm{Y}$ esto, a su vez, significaría un acuerdo - ad hoc o institucionalizado, tácito o explícito- acerca de la no intervención como una norma operativa en la política internacional. Si la alternativa a la no intervención es la intervención competitiva unida a un riesgo sustancial de provocar una confrontación entre los grandes poderes, con la consiguiente escalada de violencia, entonces un mundo en donde exista muy poca o ninguna intervención resulta preferible desde el punto de vista de cualquier cálculo utilitario. Pero este se encontraría muy lejos de ser un mundo no oneroso. El tributo de muchas guerras "pequeñas" - dentro y entre los estados - no es comparable con el posible tributo de un cataclismo nuclear, pero para los países involucrados en esos conflictos menores, de todas maneras, el precio será frecuentemente devastador. El hecho de que este precio sea más devastador que el precio impuesto por la intervención externa, sin embargo, no está claro. Por caso en que la intervención ha detenido la violencia y otro caso en que la lucha ha sido exacerbada. La intervención americana aumentó en varias veces el número de gente que sufrió los horrores de la guerra en Indochina durante el período de 15 años que terminó en 1975. 
La intervención puede limitar o no el uso de la violencia. Y puede o no favorecer el logro de una solución justa a un concepto determinado. Los hombres de buena voluntad en diferentes países, $o$ dentro de un mismo país, con frecuencia discrepan acerca de qué es lo que constituye una solución "justa" a un conflicto, pero cierta-" mente no hay ninguna seguridad de que en ausencia de una intervención externa haya de prevalecer necesariamente una determinada noción de justicia. En verdad, parece razonable presumir que la concentración de armas y recursos en las manos de gobiernos frecuentemente represivos e insensibles a la opinión mundial significa que, al menos en el Tercer Mundo, resultarán generalmente perdedoras muchas causas normalmente consideradas "justas". Este puede ser otro precio de la no intervención. Sin embargo, tampoco existe ninguna seguridad de que la intervención sí producirá un resultado "mejor".

El propósito de esta discusión no es ciertamente proponer una clara norma de no intervención, sino que comenzar a sugerir alguna de las consideraciones que deberían ser tenidas en cuenta al proponer condiciones para un mundo en el cual el impacto de la violencia -tanto dentro como entre las naciones- disminuya.

SEGURIDAD INTERNAGIONAL VERSUS SEGURIDAD NACIONAI

E1 sentido en el cual el concepto de "seguridad" ha sido usado en lạs páginas anteriores -como una reducción del impacto de la violencia dentro y entre los estados- puede parecer a algunos lectores "excesivamente estrecho. Existe una formidable tradición, originada en Europa y alimentada en los Estados Unidos, que ha definido la seguridad en términos mucho más amplios, esto es, no solamente como la seguridad de una nación estado y de sus habitantes sino también de sus intereses generales en el mundo. La seguridad se ha fortalecido, de este modo, cuando las condiciones que favorecen estos intereses están aseguradas. Desde la Segunda Guerra Mundial, para los Estados Unidos esas condiciones han incluido el manteni. miento de gobiernos amigos y no comunistas en países que aún no se encuentran bajo la regla de un gobierno comunista; asegurando el mantenimiento del vigor de una alianza básica, apoyando la vigencia de una estructura de reglas y de instituciones, influyendo para mantener una economía internacional relativamente abierta y accesible a los comerciantes e inversionistas privados, promoviendo zun 
con fuerzas militares suficientemente móviles y armadas como para intentar intervenciones efectivas dentro de sus propias regiones geográficas. La intervención de Irán en Oman, de Siria e Israel en el Líbano y de Vietnam en Cambodia no constituyen sino atisbos de lo que esos y otros poderes - como por ejemplo Brasil, la India o China-serían capaces de hacer si sus intereses se vieran fuertemente afectados. Bien puede llegar el día en que esos potenciales estados hegemónicos regionales entren en colisión con las de los super poderes.

La no intervención significa aceptar el riesgo de que en ausencia de intervención pueda prevalecer una parte que representa valores indeseables desde el punto de vista de nuestros propios intereses. Puede significar también la aceptación de un régimen y de un orden político que en el campo de los derechos humanos parezca claramente indeseable como, por ejemplo, la primacía de un brutal gobierno dictatorial. Y siempre existe la posibilidad de que la abstención de un estado no sea respondida mediante una actitud similar de abstención por parte de sus rivales, en el plano regional o global, cuya propia intervención vendría así a tener el efecto de un hecho cumplido.

Sobre todo, la no intervención significa reconocer que, en contradicción con la ampliamente conocida afirmación de Maxim Litvinov en el sentido de que "la paz es indivisible", de hecho la paz es con frecuencia divisible. En los años 1930, dicho slogan procuró prevenir a las víctimas potenciales del fascismo y del nacismo en el sentido de que si no se unían para resistir la agresión serían sacrificados separadamente. Aisladamente cada uno de ellos sería derrotado; unidos, podrían prevalecer. La advertencia de Litvinov constituyó la oración fúnebre de la Liga de las Naciones. Marcó también el fracaso del principio de la seguridad colectiva, basado en la presunción de que la ruptura de la paz en cualquier lugar debería ser motivo de igual preocupación para todos los gobiernos, independientemente de su distancia respecto al área del conflicto o la extensión de sus intereses afectados por éste, y de que todos ellos deberían actuar conjuntamente para castigar al agresor. Detrás del principio de la seguridad colectiva, yace la esperanza de la disuación: si un agresor potencial sabe que su recurso al uso de la fuerza será contestado no simplemente por el estado que piensa atacar sino por las grandes potencias múndiales en conjunto, podría ser disuadido de atacar a su enemigo, en primera instancia.

En cuanto a la Liga de las Naciones, la amenaza inherente al principio de la seguridad colectiva no tuvo jamás credibilidad. Hitler 
ción militar podría estar justificada en el caso de un proceso político similar ocurrido en un país que anteriormente no poseía ina democracia en funcionamiento a menos que hubiera clara evidencia de que aquel cambio hubiera sido provocado mediante la intervención de otra potencia. Media docena de administraciones norteamericanas sostuvieron que la sobrevivencia política de la monarquía irania era de interés vital para su país. Precisamente a causa de esas opiniones, cuando llegó el momento entre que el Sha fuera expulsado, el prestigio de los Estados Unidos quedó indudablemente deteriorado. Pero su seguridad aparentemente no lo ha sido tanto. Esto último podría pasar sólo en el caso de que el régimen sucesor del Sha decidiera mantener el petróleo iranio fuera de los mercados mundiales durante un período sustancial. Aún más serio -como causa de una drástica respuesta occidental- sería un esfuerzo realizado por Irán o por cualquier otro régimen prosélito en el Golfo Pérsico para cerrar todos los recursos petroleros de que dispone esa región del mundo. Pero esto es muy improbable que suceda.

Cabe observar aquí que existe una clara distinción entre un orden internacional congenial con los intereses de los Estados Unidos y las condiciones internacionales más apropiadas para reducir el probable impacto de la violencia dentro de y entre los estados. Estas últimas condiciones pueden ser o no congeniales con los poderes dominantes, y transmitirles una mayor sensación de seguridad que antes, mientras que otras pueden no tener efecto alguno en este campo. Posteriormente sería necesario enfatizar esa definición más estrecha de seguridad. En caso de que la revolución y la violencia entraran en un conflicto con otros valores, o con las posibles preferencias de cualquier estado o grupo de estados, este conflicto debería ponerse de manifiesto $\tan$ claramente como sea posible. Hay muchas maneras de aumentar la seguridad internacional. Algunas pueden ser empleadas por un gobierno, actuando unilateralmente. Otras requieren una amplia colaboración. Todas implican opciones muy difíciles. 